\title{
Management Method and Intelligent Technology Analysis of Construction Management
}

\author{
Jingjing Sun* \\ Chongqing Energy College, Chongqing 402260, China \\ *Corresponding author: Jingjing Sun, SunJing@cqny.edu.cn
}

\begin{abstract}
The construction industry is a critical lifeline for China's national economy's development. The growth of the building business has piqued the interest of a variety of industries. To ensure the quality of construction engineering, it is necessary to improve the technical level of construction engineering management by strengthening construction engineering management through various effective methods, following the development of The Times, and strengthening the introduction of intelligent technology. The author investigates and analyses the importance of incorporating intelligent technology into construction project management, and proposes effective strategies for incorporating intelligent technology into construction project management in the hopes of improving the quality of construction project management.
\end{abstract}

Keywords: Constructional engineering; Management method; Intelligent technology

Publication date: November 2021; Online publication: November 30, 2021

\section{Introduction}

The building of construction projects necessitates not only a longer construction cycle, but also a higher investment in terms of price and technical requirements. As a result, construction engineering management work must be given sufficient attention during the building construction engineering process. The management must strengthen the application of intelligent technology in construction project management, especially given the rapid development of intelligent technology today, in order to efficiently manage construction engineering and effectively improve the social and economic benefits of construction engineering.

2. The important significance of the introduction of intelligent technology in construction project management

\subsection{It is helpful to the effective prediction of construction risk}

At present, various new construction techniques and technical means are constantly introduced into the construction industry, and with the continuous development and progress of the society, there are more and more requirements for the performance of construction engineering. The application of intelligent technology in construction engineering management can effectively predict the various risks hidden in construction engineering. Especially in the construction link with greater risk, it is more necessary to effectively predict the construction risk in advance, so as to better avoid the occurrence of risks and reduce the occurrence of risks resulting in more losses as far as possible.

\subsection{It is helpful to improve the scientific nature of complex construction project management}

With the continuous development of the construction industry, the whole construction process of the construction project has become more complex, which puts forward higher requirements for the 
construction project management work. And the construction period of construction engineering is generally very long, during the whole construction period, it is likely to encounter a variety of factors that cannot be accurately predicted, and these factors are likely to have a great impact on the quality and progress of engineering construction. The application of intelligent technology in the administration and management of construction engineering can timely find the problems existing in the construction process of construction engineering, so as to timely formulate feasible solutions according to the problems, and then implement the administration and management of construction engineering better, and improve the effect and efficiency of administration and management.

\subsection{It is helpful for the follow-up scientific management of construction projects}

For the current construction project administration and management work, the completion of the construction project does not mean the end of the administration and management work. In the construction project completion stage, the administration and management work also need to be done well. The application of intelligent technology in the construction engineering management can realize the follow-up scientific management of the construction project. After the construction project is completed and put into use, it is likely that there will be quality problems after a period of use. At this time, it is necessary to carry out effective treatment according to various resources during the construction of the construction project. However, in the past, in the process of carrying out the construction administration and management work, there may be problems such as the collection of construction data is not complete enough, and even there is the loss of construction data. The application of intelligent technology can realize the comprehensive and efficient collection and collation of various construction data, and can safely save various data for subsequent reference, which is very beneficial to the improvement of the scientificity of the subsequent administration and management of construction projects.

\section{The effective strategy applied in the intelligent technology construction project management method}

\subsection{Strengthen the consciousness of intelligent administration and management}

Nowadays, the development of intelligent technology is very rapid, and has been widely used. The construction industry should also keep pace with the times, realize the important advantages of intelligent technology, strengthen the application of intelligent technology in construction engineering management methods, and strengthen the awareness of intelligent management ${ }^{[1]}$. Only after management personnel establish a strong awareness of intelligent management, can they better promote the intelligent development of construction engineering management and give full play to the important application value of intelligent technology. As an enterprise management and management class, we must recognize the important advantages of intelligent technology in engineering administration and management methods, and understand the important and prominent role of intelligent technology in the process of building a smart city and digital society, firm enterprise's self-confidence and determination in the application of intelligent technology in the construction engineering administration and management method, so as to better promote the development of construction engineering intelligent administration and management.

\subsection{Pay attention to the improvement of the administration and management system of intelligent buildings}

There is close relationship between management method adopted in the implementation of construction management work and construction quality and construction procedure of construction management. It also affects the benefits of construction projects themselves, including both social benefits and economic benefits. In order to improve the effect and efficiency of construction engineering management, we must 
follow the pace of the times' development, constantly improve the intelligence level of construction engineering management, so as to guarantee construction progress and construction quality of construction engineering. Therefore, construction engineering must build up intelligent construction engineering management system, and pay attention to strengthen the perfection of the system. The construction of the administration and management system can well regulate and restrict the development of the administration and management of intelligent building engineering. At the same time, it is also necessary to ensure that the construction management system covers the whole construction process, including the early construction, the construction process and the completion stage. In each construction link, we need a perfect and unified administration and management system to guide, and clear the responsibilities of each job. In addition, the reward and punishment mechanism corresponding to the intelligent construction project management system should also be constructed. Staff with outstanding performance in management and certain contributions to intelligent management should be given appropriate rewards, including spiritual encouragement and material rewards, and also should be given space for further development ${ }^{[2]}$. The staff who often appear negligent in the management work should be given corresponding punishment, so as to fully mobilize the enthusiasm of the staff to apply intelligent technology to carry out the construction project management.

\subsection{Establish a high-quality team of Intelligent construction engineering administration and management talents}

If we want to give full play to the important role of intelligent technology in the construction engineering administration and management, we need to establish a high-quality intelligent construction engineering administration and management talents team to make strong support in human resources ${ }^{[3]}$. Construction enterprise needs to realize that the construction situation of high-quality intelligent construction engineering administration and management talents team is directly related to the effect of intelligent construction engineering administration and management. Therefore, on one hand the construction enterprise should organize the staff with certain potential in the internal intelligent construction engineering administration and management. On the other hand, the construction enterprise can select from the interior process talents, and also recruit some high-quality administration and management talents from the outside, so as to inject new vitality into the administration and management work of intelligent construction engineering. Enterprise can promote management staff to use intelligent technology more flexibly through the one to one and supporting measures.

\subsection{Establish an all-round intelligent monitoring system for building engineering}

In the process of applying intelligent technology to carry out construction project management, construction enterprises should actively establish a full range of intelligent monitoring system. In order to ensure the smooth development of the administration and management of intelligent construction engineering, it is necessary to strengthen the supervision and administration and management of various infrastructure equipment, so as to lay a good foundation for the smooth application of intelligent technology in the administration and management of construction engineering. Through the establishment of a comprehensive intelligent monitoring system, not only can we give full play to the important role of intelligent technology in the administration and management of construction engineering, but also can improve the efficiency of the administration and management of construction engineering ${ }^{[4]}$. Therefore, the construction enterprises must increase the capital investment on the application intelligent technology in the administration and management of construction engineering, so as to ensure that the establishment of the monitoring system has enough financial support. Although the establishment of all-round monitoring system cannot bring direct economic benefit to enterprise, through the establishment of the system, it can 
well control the construction cost of the construction project, so as to realize the improvement of the economic benefit of the enterprise. In the process of building a comprehensive monitoring system, construction enterprise can learn from the monitoring system of other enterprises, but it should make corresponding improvement and optimization according to its own actual situation, so as to ensure that the establishment of the system in line with the requirements of intelligent building engineering management.

\section{Conclusion}

To summarize, the use of intelligent technology in the administration and management of construction engineering is critical, as it not only aids in the effective prediction of construction risk, but also aids in the improvement of the scientificity of complex construction engineering administration and management, as well as the subsequent scientific administration and management of construction engineering. To accomplish construction project management work more efficiently, construction enterprises must recognize the significant benefit of intelligent technology methods and improve their application in construction engineering administration and management.

\section{Disclosure statement}

The author declares no conflict of interest.

\section{References}

[1] Zhao X, 2020, Administration and Management Problems and Technology Application Research of Intelligent Building Engineering. Management and Technology of Small and Medium-size Enterprises (Medium Issue), 2020(09): 186-187.

[2] Yang J, 2020, Application of BIM Technology in Construction Management of Intelligent Building. Equipment Maintenance Technology, (02): 270.

[3] Xiao K, 2019, Application of Intelligent Engineering Administration and Management Technology in Construction Engineering Administration and Management. China Construction, (05): 78-79.

[4] Yang X, 2017, Research on Construction Management Method and Intelligent Technology Application. Doors \& Windows, (7): 72. 